\title{
Política y escritura de frontera en La hija extranjera de Najat EI Hachmi: la migrante como paria
}

\author{
Politics and Border Writing in La hija extranjera \\ by Najat El Hachmi: The migrant as pariah
}

\author{
Cristina Jiménez Gómez \\ Universidad de Córdoba \\ 162jigoc@uco.es
}

\begin{abstract}
The autofictional novel La hija extranjera (2015), by the Catalan-Moroccan author Najat El Hachmi, is linked to the figure of exclusion and to what, in particular, Hannah Arent called "modern pariah". Her literary writing vindicates a border thinking and the vision of a fragmentary, multiple and plural migrant female subject - contrary to the unitary male hegemonic subject - that shows, in Jacques Rancière's terms, the close relationship that literature maintains with politics.
\end{abstract}

Keywords: Najat El Hachmi, Rancière, Border Writing, pariah, migrant woman

\section{UNA ESTÉTICA DEL DISENSO: REVELAR ES CAMBIAR}

Para el filósofo Jacques Rancière (Argel, 1940), la política implica hablar de la división o repartición de lo sensible -le partage du sensible-, lo que pone al descubierto la conformación de un común que define "los modos del ser, del hacer, del decir y del aparecer (ser visible o no)" reconocidos bajo un orden policial (Rancière, 2011a, p. 12) pero, también, la existencia de las partes excluidas de ese común válido -del habla y de la visibilidad común. A lo largo de la Historia, lo común se ha repartido entre unos pocos quedando fuera de esta distribución otros como los esclavos, el proletariado, los inmigrantes, los homosexuales y las mujeres; ${ }^{1}$ todos

\footnotetext{
${ }^{1}$ La cuestión fundamental del Otro y de los otros es muy significativa en el pensamiento feminista de Hélène Cixous, especialmente si tenemos en cuenta que creció en la Argelia francesa y procede de
} 
ellos sin voz y sin visibilidad. A este respecto, la estética está en estrecha relación con la política en tanto que las prácticas artísticas son "maneras de hacer" que intervienen no solo en la división o repartición de lo sensible sino, también, en su reconfiguración:

La política consiste en reconfigurar la repartición de lo sensible que define lo común de una comunidad y que introduce los sujetos y los objetos nuevos, en hacer visible lo que no lo era y en hacer escuchar como hablantes a aquellos que solamente eran percibidos como animales ruidosos. Este trabajo de creación de disensos constituye una estética de la política. (Rancière, 2011b, pp. 34-35)

Será precisamente, a través de la política, el modo en cómo los excluidos del reparto primordial se afirmen como seres visibles y dotados de palabra frente a aquellos que previamente los excluyeron. En este contexto, la esfera estética, el arte en general, tiene un papel fundamental para refigurar una nueva repartición de lo sensible a través de un acto de disenso:

La política no necesita barricadas para existir. Pero sí necesita que una manera de describir la situación común y de contar a sus participantes, que se oponga a otra y que se oponga significativamente. También es por ello que sólo existe en determinados momentos: esto no quiere decir que se dé mediante destellos fugitivos sino mediante la construcción de escenas de dissensus. Un momento no es simplemente una división del tiempo, es otro peso puesto en la balanza donde se pesan las situaciones y se cuentan los sujetos aptos para comprenderlas, es el impulso que desencadena o desvía un movimiento: no una simple ventaja tomada por una fuerza opuesta a otra, sino un desgarro del tejido común, una posibilidad de mundo que se vuelve perceptible y cuestiona la evidencia de un mundo dado. (Rancière, 2010, p. 11)

Disenso se opone, así, a consenso y se relaciona, según Rancière (2011a, p. 14), con otra manera de hacer (el arte) donde se proponen "nuevas distribuciones sobre las maneras de hacer, las maneras de ser, las maneras de decir y las formas de visibilidad". Arte y política no son, pues, dos entidades separadas, sino que deben ser puestas en vinculación porque ambas están ligadas en tanto la redistribución de identidades, de espacios y tiempos, de lo visible y lo invisible. La estética del disenso, que permite cuestionar la evidencia dada, guarda vínculos con la escritura comprometida por la que abogaba Jean-Paul Sartre (1957, p. 47), porque "el escritor com-

una familia de ascendencia judía: "Todo lo aprendí de ese primer espectáculo: vi cómo el mundo blanco («francés») superior plutocrático, civilizado instituía su poder a partir de la represión de poblaciones que se hacen a veces «invisibles» como son los proletarios, los trabajadores inmigrados, las minorías que no tienen el «color» adecuado. Las mujeres. Invisibles en calidad de humanos. Pero por supuesto, percibidos en calidad de instrumentos, sucios, tontos, perezosos, mentirosos, etc. Gracias a la magia dialéctica aniquiladora. Vi cómo los grandes y hermosos países «avanzados» se erigían expulsando al extranjero; excluyéndolo pero no demasiado lejos: en la esclavitud”. (Cixous, 1995, p. 24) 
prometido sabe que la palabra es acción; sabe que revelar es cambiar y que no es posible revelar sin proponerse el cambio". Precisamente, Najat El Hachmi (Nador, 1979) en su novela autoficcional La hija extranjera, premiada con el Sant Joan de la literatura catalana en 2015 , presenta la cuestión identitaria en una joven migrante de segunda generación, de origen marroquí y crecida en una ciudad catalana del interior, como un elemento de transgresión de lo dado. En este sentido, la novela contiene una fuerte potencia transformadora en tanto que representa, explica y revela el mundo desde la visión de una mujer migrante en contra de la lógica cultural dominante de una y otra sociedad -la catalana-europea y la marroquí-islámica. Veremos pues cómo, a través de una protagonista periférica, plural y dialógica, El Hachmi utiliza la palabra para visibilizar y reivindicar lo diferente, lo extraño y lo contradictorio en una realidad que generalmente permanece oculta en la literatura donde la perspectiva dominante ha sido la del hombre blanco de clase media.

La propia escritora, con motivo de una entrevista concedida al diario digital Público en 2015, ya afirmó que su escritura responde a un intento de dar voz a aquellos seres que están ausentes o se les ha hecho invisibles -los hijos de la inmigración- tanto en la creación literaria como en la vida real:

Escribir responde al intento de plasmar en una creación literaria una realidad que no se ve normalmente. No creo que la literatura se deba centrar única y exclusivamente en reflejar la realidad, pero creo que es significativo que haya un tipo de personas que nunca aparecen en creaciones culturales, ya sea literarias y no, y es importante no perpetuar esta invisibilidad. (El Hachmi, 2015b, párrafo 3)

El Hachmi sabe muy bien que la palabra es acción porque revelar implica, en mayor o menor medida, cambiar y transformar la realidad que nos rodea. Su escritura consigue hacer audible la voz de grupos socio-culturales oprimidos, como las mujeres migrantes, interpelando al lector a modificar la manera en que ve su realidad. La autora, a través del pensamiento, la palabra y el comportamiento de su protagonista en La hija extranjera, consigue hacer visible el yo de la mujer migrante, vinculado con dos sociedades - la marroquí y la catalana- que le exigen unos modos de ser y estar en el mundo. No obstante, esta sujeta migrante no está dispuesta a conformarse con la posición subalterna que el país de acogida le ofrece pero, tampoco, con el rol normativo de esposa y madre que su cultura originaria le demanda obligatoriamente. Por un lado, en el país de acogida, ella se sabe un ser extraño y ajeno, un ser abyecto $^{2}$ confinado, junto a su madre, al extrarradio de la ciudad

\footnotetext{
${ }^{2}$ Término acuñado, desde una perspectiva psicoanalítica, por Julia Kristeva en su ensayo Poderes de la perversión (1980). La teórica explica que el niño debe renunciar a una parte de sí para ser reconocido como sujeto por lo que, al igual que tiene que aprender que caca, orina y vómito son sustancias sucias y no objetos de placer, aprende a que debe diferenciarse de la entidad materna para entrar, según la Ley del Padre, en el mundo de la cultura, que se asocia a lo masculino. Por tanto, la abyección o lo abyecto se relaciona directamente con todo aquello -hábitos socio-culturales, formas de
} 
y a realizar trabajos precarios y mal remunerados. Por otro lado, también sometida al Patriarcado de la cultura islámica, ella es excluida del espacio público y "desterrada" al espacio de lo doméstico donde también sigue prevaleciendo la voz del varón. En ambos casos, el Estado de una y otra sociedad se encargan, por consiguiente, de conformar un ser periférico, situado en los márgenes de la sociedad, sin visibilidad y sin voz.

Solo en el momento en que la joven es consciente de su marginalidad como migrante y como mujer se inicia el cambio para transformar su realidad cotidiana. De hecho, ella se interpela a sí misma adoptando la perspectiva de los Otros - occidentales- para criticar la discriminación que, a consecuencia de su clase, raza, origen y religión, sufre el colectivo de los migrantes. En comparación con sus compañeros de instituto, ella es la intrusa y la que no se adapta a la norma y, por más que lo intente, nunca será vista como una igual a ellos. Muy significativo es el uso del adverbio "casi" en alusión a la imposibilidad de lograr ser aceptada plenamente por los Otros:

¿De qué te extrañas? Esa es la vida normal, es la tuya la que no encaja, tú eres la intrusa. Tú, que tienes una madre que limpia en sus casas, y aún gracias que alguien la pudo aceptar en su casa a pesar de la raya en medio, la frente regia de rifeña y el pañuelo en la cabeza. [...] No tienes ningún motivo para quejarte, como hablas su lengua igual o mejor que ellos casi no recuerdan de dónde eres o quién eres. Casi. (El Hachmi, 2015a, p. 26)

De la misma manera, la joven se interpela sobre las "costumbres" -patriarcalesde su cultura marroquí-islámica que la enmarcan en un matrimonio de conveniencia. De forma irónica, ella se dice que debe estar agradecida de casarse con un hombre, su primo, porque, al menos, lo conocía. Era un matrimonio que ya estaba reglado entre las familias desde su nacimiento, cuando sus futuros suegros le regalaron un anillo de oro: “¿Qué más quieres? ¿Cuántas mujeres de tu pueblo han tenido ese privilegio, casarse con un hombre al que conocían?” (p. 45). La palabra, sea verbalizada o no en tanto manifestación de su pensamiento más secreto, deja ver a una sujeta transgresiva y crítica con lo estipulado, lo que se vincula con la acción, con el hacer en el mundo.

\section{LA PARIA Y LA PLURALIDAD COMO ACCIÓN POLÍTICA}

El término paria, que en lengua tamil significa tambor (parái) -instrumento cuya piel es considerada impura y solo puede ser tocada por los intocables, la clase

comportamiento sexual, rituales religiosos, identidades, etc.- que la sociedad tiende a condenar y, por ende, se vincula con las prácticas transgresivas en general. Kristeva (2006, p. 11) sostiene que lo abyecto es "aquello que perturba una identidad, un sistema, un orden", lo que "no respeta los límites, los lugares, las reglas". 
social más baja de la India- designa al sujeto y, más concretamente, a los grupos oprimidos -como, tradicionalmente, lo han sido los judíos y los negros-a los que les "son negadas sistemáticamente las condiciones que posibilitan una vida política, social y privada" (Rayas, 2011, p. 12). Hannah Arendt (1993) relacionó lo paria ${ }^{3}$ con la condición existencial misma de los judíos en la modernidad, marcada por la abyección pero, también, por el extrañamiento propio y ajeno al saberse, marginales y marginados. El paria no solo es rechazado por la sociedad en la que debe integrarse, sino que, también, se ve obligado a "sacrificar" su propia naturaleza, su yo, en el intento de conseguir esa existencia social y dejar de lado la situación de marginalidad. Explica, pues, que el paria se enfrenta a una situación ambigua y torturante debido a la carencia y a la permanente búsqueda de su lugar en el mundo. En este contexto, Arendt explicará que hay diferentes figuras del paria atendiendo a las distintas actitudes que el sujeto excluido presenta ante lo impuesto o lo otorgado. De ahí que la teórica política alemana, de origen judío, reivindicara el sentido de pluralidad como condición de la existencia humana -algo esencial para la vida política ${ }^{4}$ puesto que somos individuos únicos y diferenciados entre sí. Para Arendt, la pluralidad es condición misma de la acción, es decir, la acción política que se da en la esfera de lo público. Como afirma Neus Campillo:

El acceso filosófico a lo político que el ser-en-el-mundo representa para Arendt se encuentra en la estructura del ser-con, como mundo compartido con otros, ser-con-otros. [...] La respuesta de Arendt es un estar con Heidegger contra Heidegger, pues afirma la importancia de la existencia como ser-en-el-mundo y del ser-con-otros para la posibilidad de lo político. (Campillo, 2005, p. 94)

Esta pluralidad que Arendt (2005, p. 15) estima primordial para la acción política la observa en la figura del paria, quien, en su intento de insertarse a la vida europea y salir de su existencia como marginado social, responderá transformándose bien en advenedizo o parvenu -el que reniega de su judeidad con el fin de ser reconocido y poder asimilarse en otra sociedad-, o bien en paria consciente, término tomado del escritor anarquista francés del siglo XIX Lazare (1992) y relacionado con el despertar y el desarrollo de la conciencia política de los judíos europeos para crear una nación. Se alude, pues, al sujeto que no solo no pretende olvidar su propia

\footnotetext{
${ }^{3}$ En el siglo XXI, el filósofo polaco-británico de origen judío Z. Bauman (2005) también aborda lo paria en la modernidad, época caracterizada por la producción de una cultura de "residuos humanos" debido a "poblaciones superfluas" de emigrantes, refugiados y demás parias que, al no poder ser ya reabsorbidas por el "primer mundo", son eliminadas, recicladas o, por lo menos, invisibilizadas en las sociedades contemporáneas.

${ }^{4}$ Arendt dirá que "la acción, única actividad que se da entre los hombres sin la mediación de cosas o materia, corresponde a la condición humana de la pluralidad, al hecho de que los hombres, no el hombre, vivan en la tierra y habiten el mundo. [...] Esa pluralidad es específicamente la condición -no solo la condición sine qua non, sino la conditio per quam - de toda vida política”. (1993, p. 22)
} 
identidad y sus raíces, sino que las reivindica en la esfera pública y política. En este contexto, Arendt (2004, p. 61) definirá una relación en términos de tensión que mantiene unidos al paria consciente y al parvenu. En La hija extranjera, esta tensión se materializa en una paria ambivalente y movediza entre dos culturas que le permiten reivindicarse como una mujer cambiante y plural como resultado de una identidad híbrida, ${ }^{5}$ marroquí y catalana. La subjetividad múltiple, contradictoria y fragmentaria en la ficción termina siendo la herramienta más potente para subvertir los discursos de poder que privilegian a un sujeto varón homogéneo en sociedad.

La ausencia de unos patrones identitarios fijos, sobre lo que se sustenta cualquier Estado-nación, y la presencia, por el contrario, de unos patrones fluctuantes e híbridos en el yo migrante femenino provoca que, en los primeros momentos, la protagonista sufra el hostigamiento de dos fuerzas políticas, culturales y sociales que la dividen y cercenan. Surge, así, el conflicto interior al que ella logrará imponerse no siendo más para los demás sino para ella misma como la propia autora, identificada con su personaje, lo avisa al comienzo de la novela: "No seré más para vosotros. Desde ahora seré para mí. Para mí o para quien quiera, pero no para ninguno de los que me queréis sesgada, escindida". También, en el prólogo de su obra autobiográfica Jo també sóc catalana (2004), Najat recoge esa sensación de enclaustramiento interno entre dos mundos culturales que no la dejan ser en su pluralidad, cosa que sí le permite hacer la escritura. La autora reivindica la necesidad de un pensamiento de frontera que se relaciona con una manera de hacer, de actuar, de ser y de sentir para "dejar madurar un pensamiento que ya no es el de nuestros padres, pero que no es del todo de las personas que nos rodean, los autóctonos" (El Hachmi, 2004, pp. 4-5).

En la novela, esta condición híbrida del yo será percibida por los demás como un factor de riesgo en tanto que constituye una potencial amenaza para la existencia de cada una de las sociedades, la catalana y la marroquí, con las que el personaje se vincula. Esto condiciona que la protagonista se sienta obligada a cumplir las expectativas de su madre -subscribir todos los ritos, costumbres y valores de la cultura originaria-, y a tener que integrarse social, intelectual y laboralmente en la sociedad de acogida:

El conflicto entre las dos posiciones, que pasa a través de una crisis personal que roza la neurosis, primero la lleva a cumplir con las expectativas de la madre; luego, con fuerza y valentía no sin consecuencias, la conduce a emprender la trayectoria de la emancipación personal, gracias a unas estrategias de cambio personal hacia una pluralidad cultural apta para facilitar la integración en el tejido social y cultural catalán. (Darici, 2017, p. 107)

\footnotetext{
${ }^{5}$ Arnau i Segarra (2016, p. 248) se refiere a que las obras de los escritores migrantes, que llegaron a Cataluña por motivos de reagrupación familiar como El Hachmi, pueden enmarcarse dentro de las llamadas "escrituras del yo híbrido", propias de sujetos migrantes y de identidades transfronterizas que están en permanente tensión y deben negociar cada día su lugar en el mundo.
} 
Pero, en este proceso, también aflora su imposibilidad de adoptar los preceptos colonialistas y paternalistas de Occidente, los cuales se hacen patentes cuando "los hombres blancos tratan de salvar a las mujeres de piel morena de los hombres de piel morena" (Spivak, 2009, p. 115). Son las sobredeterminaciones que la visión eurocéntrica y colonialista impone sobre la raza, la religión, la cultura y la sociedad consideradas inferiores y más atrasadas, herméticas y machistas. No sorprende, entonces, que surjan en la protagonista - alter ego de la autora- recuerdos, pensamientos $\mathrm{y}$ acciones contradictorios que dejan ver, en ocasiones, una sensación general de orfandad, desamparo y desarraigo, lo que en términos del antropólogo francés Marc Augé se denomina como un no-lugar, ${ }^{6}$ es decir, un espacio de transición, que no se vincula con la memoria y la identidad del individuo. Sometida a la opresión y a las fuerzas de poder tanto dentro del seno familiar como fuera de él, por ejemplo, cuando asiste a una entrevista en el ayuntamiento de la ciudad para optar a ser mediadora de la comunidad magrebí, la protagonista se encuentra en un lugar donde su identidad se distorsiona. Se trata de un lugar artificialmente adulterado por las interferencias políticas, culturales y sociales de la comunidad de acogida que penetran y alienan el yo. Ante todo, se concibe como un espacio de exclusión y asignación: lo primero que le insinúa la hija del alcalde es que, para conseguir el trabajo, no debe llevar el pañuelo o el hiyab. Precisamente, este fue el motivo por el que despidieron a la antigua mediadora. También muy joven y de origen marroquí, ella empezó a ser mirada con reticencias por sus compañeros cuando, después de casarse con un primo suyo, decidió llevar el pañuelo: "Hemos intentado hablar con ella, pero dice que se lo pone porque quiere y que no se lo quitará. Así que después de la baja por maternidad ya no seguirá trabajando para nosotros" (p. 160). En un proceso paulatino, la subjetividad del colonizado ${ }^{7}$ se va asociando con el atraso, lo inferior, lo malo.

$\mathrm{El}$ intento de funcionar en dos sociedades y en dos culturas, lleva a la narradora a darse cuenta de las coacciones y males de ambos mundos y de la necesidad de reivindicar su verdadero yo, ajeno a los mandatos externos. En su camino de ajustarse obsesivamente a los valores occidentales -también patriarcales- de la sociedad catalana, entre ellos el estereotipo femenino europeo de delgadez y cabello liso como cualquier otra "mujer blanca", se subleva contra la discriminación ejercida sobre la comunidad marroquí. Por tanto, el discurso y la acción de la protagonista se fundan en la pluralidad, entendida no únicamente en relación a su diferencia

\footnotetext{
${ }^{6}$ A principios de los años noventa, Marc Augé acuñó el concepto de "no-lugar" para referirse a los lugares de tránsito (un aeropuerto, una habitación de hotel), dominantes en las sociedades "sobremodernas", que no son sede de la identidad y subjetividad del individuo. Augé (2000, p. 83) dirá que "si un lugar puede definirse como lugar de identidad, relacional e histórico, un espacio que no puede definirse ni como espacio de identidad ni como relacional ni como histórico, definirá un no lugar".

${ }^{7}$ Sobre esta cuestión, Natalia Álvarez (2010, p. 14) explica cómo se produce la "alienación del colonizado" y "la constitución de la subjetividad del colonizado".
} 
y diversidad étnica, cultural y religiosa sino, también, en cuanto a la actualización de su conciencia durante la actividad del pensamiento en el mundo. En el permanente diálogo silencioso del yo consigo mismo, ella deja aflorar a una sujeta indefinida, fragmentaria y cambiante que reivindica otra manera de funcionar en el espacio privado y público.

\section{OTRA MANERA DE FUNCIONAR: MUJER, HIJA Y MIGRANTE}

La hija extranjera narra la historia de una joven que nació en Marruecos y creció en Cataluña, con la compleja realidad cultural, social y personal que acarrea el hecho de pertenecer a una familia inmigrada marroquí constituida por un núcleo monoparental -la madre-, con lo que eso implica de estigmatizador dentro de la cultura islámica. Por motivos de reagrupación familiar, madre e hija se trasladaron a Cataluña siguiendo al marido/padre, situado ya allí. Sin embargo, dicha reagrupación no llega a producirse porque, una vez allí, las dos mujeres descubren que aquel ya se había unido a otra mujer. La ausencia del marido y de la figura paterna llevan a la madre y a la hija al ostracismo, a un destierro y aislamiento forzoso que repercute en el ámbito social, económico, político y jurídico pues pasan a ser consideradas "peligrosas" y "defectuosas" para la estabilidad del statu quo patriarcal, marroquí y catalán. Aparece, así, la culpa y el "sentido del honor" -infundados por el Patriarcado- en la mujer.

En este sentido, la figura materna, marginada y juzgada, descarga su frustración emocional sobre su hija que, tampoco, puede deshacerse de tal carga. La madre induce, primero, a su hija a cumplir con sus "deberes femeninos" y, después, la hace culpable de su fracaso ante lo que estipula la Ley del Padre. Como dirá V. Sau (1995, p. 92) "la hija se hace rehén del victimismo de la madre y se convierte en su sostén emocional" y, así, la primera también es la que se hace cargo del "honor" y la reputación de la segunda. Frente al espejo, la narradora se mira y, de forma introspectiva, reflexiona sobre su decisión de casarse con su primo Driss. Una decisión que, según su entorno más cercano, era fruto de su libre elección, lo que ella misma también se obliga a creer pero que, en realidad, sabemos viene forzada por la gran culpa que, por vía materna, ha adquirido. Ella debe ser una "buena mujer marroquí" y no una faq shger o "partidora de tareas" - una mujer que, según las amigas marroquíes de la madre, no es ni "discreta" ni "tranquila"-. Solamente así, a través del cumplimiento de la hija con el Patriarcado, la madre conseguirá ser "libre": "Me miro a los ojos y me insisto: Cásate y tu madre será libre" (p. 46).

Sin embargo, en otros momentos, la voz de la enunciación se rebelará contra lo estipulado por medio de un pensamiento transgresivo y dentro de su entorno más íntimo. Ella que, ha obtenido una de las más altas calificaciones en la selectividad, examen previo de ingreso a la Universidad, quiere continuar sus estudios en Barce- 
lona como cualquier otro compañero de su instituto. En este sentido, es muy significativo que, mientras que sus escasísimos recuerdos sobre su primera infancia en Marruecos son confusos y vienen dados por el ámbito doméstico y materno, la inmensa mayoría de sus experiencias dadas durante los años de adolescencia -la etapa más determinante en el forjamiento de la personalidad del individuo- han transcurrido en la sociedad catalana, especialmente en su sistema de escolarización, donde ha puesto nombre a su realidad a través de la lengua catalana. Sobre esta cuestión, Rosa Aparicio (2007, p. 121) reivindica el término de segunda generación, referido a los hijos de los trabajadores inmigrantes que han nacido o crecido en el país de residencia de sus padres, no solo desde un sentido biológico sino, sobre todo, histórico y político, porque se vincula con nuevas, distintas y transgresivas formas de pensar y proceder en estos hijos.

Por eso, la protagonista usa la lengua catalana no solo con un fin práctico para relacionarse en el ámbito académico y público, sino, sobre todo, para nombrar $\mathrm{y}$ aprehender intencionalmente un mundo distinto al de su madre puesto que esta lengua, donde se materializa su pensamiento transgresivo, le hará ser consciente de la imposibilidad de traducir su mundo al mundo materno. De hecho, las pocas palabras que ha aprendido de la que llama "nuestra-su lengua" -la materna-, ajena y extraña para ella, tienen que ver con el mundo doméstico que su progenitora se ha encargado de enseñarle. En ocasiones, la hija tiene muchas dificultades para encontrar la correspondencia de la palabra catalana en la lengua bereber de su madre -el amazigh- percatándose, así, de cuán lejos está de ella. En la novela, la madre representa, en términos de Victoria Sau, una "maternidad impostada", patriarcal:

¿Cómo tendría que llamar a la tetera del café? Zaghlasht, abarrad, tan nítidamente diferentes en nuestra-su lengua y yo no soy capaz de encontrar la correspondencia. De repente, este desajuste léxico, tan insignificante, tan banal, me ha hecho recordar cuán lejos estoy de ella, de su mundo, de su manera de ver y entender las cosas. Por más que traduzca, por más que intente verter las palabras de una lengua a otra, nunca lo conseguiré, siempre habrá diferencias. Pese a ello, traducir continúa siendo una distracción dulce, una forma tangible al menos, de desear llevar a cabo este acercamiento de nuestras realidades, que me ha sido útil desde que vinimos aquí. (El Hachmi, 2015a, p. 19)

Incluso, la narradora distingue entre "la lengua de mi pensamiento" - la catalana- y la "lengua de mi madre". Con la primera, que se vincula con lo interior, lo más íntimo y secreto del yo, ella puede expresar su propio pensamiento, que se torna transgresivo por revelarse en un entorno doméstico hostil y opresivo. Lo materno remite permanentemente a la muerte y al enclaustramiento doméstico como el color amarillento de la cocina, de la casa, de su vida: "de un amarillo mortecino, sin alma, ni pasión ni matices de ningún tipo, un amarillo insípido” (p. 16). Significativo es el momento en que la joven recuerda la contradicción que le produjo cuando, en el colegio de su nuevo país, le explicaron que había un día dedicado a todas las ma- 
dres y que, por tanto, había que felicitarlas. Pero, en su lengua materna, el día de alguien significaba la muerte de esa persona, de ahí la confrontación de la madre ante las felicitaciones inocentes de su hija por aquel entonces: “¿Qué pasa, acaso quieres que me muera?" (p. 64). Esta anécdota, dada en la vida íntima y cotidiana, quedará grabada en su mente y, después, en su día, durante la celebración del casamiento con su primo Driss, la rememorará para comprender lo que estaba a punto de vivir: su muerte en vida. Así pues, la lengua de su madre resemantiza una realidad de angustia, de oscuridad y de muerte tal y como ella confirma: "si digo es mi día en la lengua de mi madre, querría decir que me tengo que morir, que está escrito que hoy me voy a morir" (p. 64).

Por el contrario, en la lengua de "su pensamiento" es donde se construye una disposición transgresiva y política hacia un mundo que la reduce, la excluye y la margina. La narradora deconstruye el lenguaje y el mundo doméstico mediante una visión erógena de su entorno más inmediato. La casa, la cocina y todo lo relacionado con las actividades domésticas, como amasar y preparar el té, estimulan sus sentidos y la activan sexualmente hasta llevarla fuera de sí y liberar su verdadero yo. Un yo que, aprisionado, permanecía oculto bajo la piel. La joven describe el proceso de fermentar y amasar como una experiencia erótica y placentera. El tacto fresco del fermento, recién salido de la nevera, y la forma en que se iba aglutinando a medida que lo amasaba, le producían un extraño placer en las yemas de sus dedos. Esta extraña y nueva sensación se irradiaba, de forma imparable, por todas las partes de su cuerpo y producía en ella un placer que, al estar prohibido, se multiplica de forma exponencial:

Lo que me ocurre en las manos se expande, al principio, por todos mis rincones, lo puedo percibir aunque no conozca sus nombres y no pueda imaginarme su anatomía, me estremezco entera por todas partes de un modo que nadie puede ver; y después parezco ser yo la que me expando por todas partes. Debe ser lo que llaman comunión con el mundo, un éxtasis íntimo y secreto. Esconder esta sensualidad exagerada me ha costado siempre un esfuerzo enorme. (El Hachmi, 2015a, pp. 17-18)

Esta excitación extraña y transgresiva aparece especialmente cuando la narradora quiere evadirse de un entorno familiar cerrado, asfixiante y censurador. Por eso, cuando las chismosas amigas marroquíes de su madre -la joven las llamará "gallinas cluecas" - llegan a la casa para tomar el té y chismosear sobre lo que hace o no hace una buena mujer marroquí, ella piensa en huir al baño para provocarse un orgasmo. De la misma manera, como un acto subversivo, ella rememora la excitación que, a los doce años, le causó el contacto físico con el camionero que se llevaba los conejos de la granja donde trabajaba su madre. El camionero la "sobó" dentro de la cabina de su camión y, en ese preciso momento, empezó a descubrir y conocer su sexualidad, acallada y censurada siempre por su madre y su cultura materna: "mi madre sí 
que habría tenido razón, yo era una descarada y lo había provocado. Y tenía más razón aún porque, en su forma de sobarme, en la manera en que me manoseaba el culo, encontré una excitación nueva" (p. 61).

\section{CONCLUSIÓN}

El Hachmi, en una entrevista concedida para El Periódico, manifestó que nunca renunciará a su origen como escritora $(2015 \mathrm{c})$. Con motivo de la publicación de La hija extranjera, la autora explica que, en su novela, no solo habla de la relación madre-hija en abstracto, sino de una madre y una hija en un entorno concreto. La realidad de las mujeres amazigh en una situación determinada, marcada por la migración, posibilita abrir el discurso literario a un proceso reflexivo sobre cuestiones como la identidad y la subalternidad en relación con el género. Algo que, como ha estudiado Cristian Ricci (2014), es habitual en los autores imazighen-catalanes como Najat El Hachmi, cuya escritura establece un espacio de reflexión sobre un proceso identitario que se torna abierto, cambiante $\mathrm{y}$, sobre todo, transgresivo en un entorno normativo y patriarcal.

Hemos demostrado que la escritora configura, en términos de Rancière, una política puesto en tanto que su práctica discursiva consigue una redistribución de lo visible y lo invisible, de las identidades y de los espacios en un sentido material y simbólico. A través del pensamiento, habla y acción de su protagonista, El Hachmi pone en primer plano la precariedad y marginalidad del migrante, los binarismos policiales encargados de la construcción identitaria en contextos migratorios y cómo estos están dirigidos especialmente hacia la mujer. Se visibiliza, así, una realidad que luego la migrante se encarga de reconfigurar en el mundo de la ficción: primero, subvierte el significado de lo doméstico a través de un pensamiento y una sexualidad no normativos en su cultura originaria; segundo, accede al espacio público de la sociedad receptora y lo desarticula desde su situación de subalterna; y, tercero, deshace los lazos patriarcales que la unen con su madre para lograr emanciparse emocional y económicamente. Por tanto, como lectores, estamos ante un personaje que cambia continuamente de perspectiva producto de su identidad cultural fluctuante y no unívoca, lo que permite hacer visible individuos, cosas y hechos que no se veían, que estaban ocultos y dispersos. 


\section{BIBLIOGRAFÍA}

Álvarez, N. (2010). Palabras desencadenadas: aproximación a la teoría literaria postcolonial y a la escritura hispano-negroafricana. Zaragoza: Prensas Universitarias.

Aparicio, R. (2007). La integración de las segundas generaciones en Europa: El Estudio EFFNATIS (eficacia de las políticas de integración de los hijos de inmigrantes). En A.M. López Sala, y L. Cachón (coords.), Juventud e inmigración. Desafios para la participación y para la integración (119-136). Las Palmas de Gran Canaria: Consejería de Empleo y Asuntos Sociales del Gobierno de Canarias.

Arendt, H. (1993). La condición humana. Barcelona: Paidós.

Arendt, H. (2004). La tradición oculta (Gómez Ibáñez, trad.). Barcelona: Paidós.

Arendt, H. (2005). Una revisión de la historia judía y otros ensayos. Buenos Aires: Paidós.

Arnau i Segarra, P. (2016). L'hybridité identitaire dans une littérature émergente: l'écriture du «moi» hybride dans l'œuvre autobiographique des écrivains catalans d'origine maghrébine. Babel, 33, 247-259. Consultado el 3 de mayo de 2019 en http://journals.openedition. org/babel/4540.

Augé, M. (2000). Los no lugares. Espacios del anonimato. Barcelona: Gedisa.

Bauman, Z. (2005). Vidas desperdiciadas: La modernidad y sus parias. Buenos Aires: Paidós.

Campillo, N. (2005). «Mundo»y «Pluralidad» en Hannah Arendt. Intersticios, 9 (22/23), 87-100.

Cixous, H. (1995). La risa de la medusa: ensayos sobre la escritura (A.M. Moix, y M. DíazDiocaretz, trad.). Barcelona: Anthropos.

Darici, K. (2017). Literatura transnacional en Cataluña: La filla estrangera de Najat El Hachmi. Diablotexto Digital, 2, 106-134.

El Hachmi, N. (2004). Yo también soy catalana (M. Repinecz, trad.). Barcelona: Columna.

El Hachmi, N. (2015a). La hija extranjera (R.M. Pratz, trad.). Barcelona: Planeta.

El Hachmi, N. (2015b). Najat El Hachmi, otra voz sobre Europa, Cataluña, el Is-lam, la inmigración. Público. Entrevista con A.M. Iglesia. Consultado el 4 de mayo de 2019 en https://elasom brario.com/najat-el-hachmi-otra-voz-sobre-europa-cataluna-el-islam-la-inmigracion/.

El Hachmi, N. (2015c). Najat el Hachmi: «No renunciaré a mi origen como escritora». Entrevista con Ernest Alós. Consultado el 6 de noviembre de 2019 en https://n9.cl/w2o4.

Kristeva, J. (2006). Poderes de la perversión. México D.F.: Siglo XXI.

Lazare, B. (1992). Juifs et antisémites (P. Oriol, ed.). París: Allia.

Rancière, J. (2010). Momentos políticos. Buenos Aires: Capital Intelectual.

Rancière, J. (2011a). El destino de las imágenes (M. Gajdowski, trad.). Buenos Aires: Prometeo.

Rancière, J. (2011b). El malestar en la estética (V. Petrecca, y G. Burello, trad.). Buenos Aires: Capital Intelectual.

Rayas, E.J. (2011). El concepto de paria en la obra de Hannah Arendt. Guadalajara (México): Universidad de Guadalajara.

Ricci, C. (2014). ¡Hay moros en la costa!: Literatura marroqui fronteriza en castellano y catalán. Madrid: Iberoamericana.

Sartre, J.P. (1957). ¿Qué es literatura? (A. Bernárdez, trad.). Buenos Aires: Losada.

Sau, V. (1995). El vacio de la maternidad: madre no hay más que ninguna. Barcelona: Icaria.

Spivak, G. (2009). ¿Pueden hablar los subalternos? (M. Asensi, ed.). Barcelona: MACBA. 